\title{
Severe Hypertensive Disorders of Pregnancy in
}

\section{Eastern Ethiopia: Comparing the Original WHO and Adapted sub-Saharan African Maternal Near-Miss Criteria}

This article was published in the following Dove Press journal:

International Journal of Women's Health

\author{
Abera Kenay Tura $\mathbb{I}^{1,2}$ \\ Sicco Scherjon ${ }^{2}$ \\ Jelle Stekelenburg ${ }^{3,4}$ \\ Jos van Roosmalen ${ }^{5,6}$ \\ Thomas van den Akker ${ }^{5,6}$ \\ Joost Zwart ${ }^{7}$ \\ 'School of Nursing and Midwifery, \\ College of Health and Medical Sciences, \\ Haramaya University, Harar, Ethiopia; \\ ${ }^{2}$ Department of Obstetrics and \\ Gynecology, University Medical Centre \\ Groningen, University of Groningen, \\ Groningen, The Netherlands; \\ ${ }^{3}$ Department of Health Sciences, Global \\ Health, University Medical Centre \\ Groningen, University of Groningen, \\ Groningen, The Netherlands; \\ ${ }^{4}$ Department of Obstetrics and \\ Gynecology, Leeuwarden Medical \\ Centre, Leeuwarden, The Netherlands; \\ ${ }^{5}$ Athena Institute, Vrije Universiteit \\ Amsterdam, Amsterdam, The \\ Netherlands; ${ }^{6}$ Department of Obstetrics \\ and Gynaecology, Leiden University \\ Medical Centre, Leiden, The \\ Netherlands; ${ }^{7}$ Department of Obstetrics \\ and Gynaecology, Deventer Ziekenhuis, \\ Deventer, The Netherlands
}

Objectives: To assess life-threatening complications among women admitted with severe hypertensive disorders of pregnancy and compare applicability of World Health Organization (WHO) maternal near-miss (MNM) criteria and the recently adapted sub-Saharan African (SSA) MNM criteria in eastern Ethiopia.

Methods: Of 1,054 women admitted with potentially life-threatening conditions between January 2016 and April 2017, 562 (53.3\%) had severe preeclampsia/eclampsia. We applied the definition of MNM according to the WHO MNM criteria and the SSA MNM criteria. Logistic regression was performed to identify factors associated with severe maternal outcomes (MNMs and maternal deaths).

Results: The SSA MNM criteria identified 285 cases of severe maternal outcomes: 271 MNMs and 14 maternal deaths (mortality index 4.9\%). The WHO criteria identified 50 cases of severe maternal outcomes: $36 \mathrm{MNMs}$ and 14 maternal deaths (mortality index 28\%). The MNM ratio was 36.6 per 1,000 livebirths according to the SSA MNM criteria and 4.9 according to the WHO criteria. More than $80 \%$ of women in both groups had MNM events on arrival or within 12 hours after admission. Women without antenatal care, from rural areas, referred from other facilities, and with concomitant hemorrhage more often developed severe maternal outcomes.

Conclusion: Regarding hypertensive disorders of pregnancy, the SSA tool is more inclusive than the WHO tool, while still maintaining a considerably high mortality index indicating severity of included cases. This may enable more robust audits. Strengthening the referral system and improving prevention and management of obstetric hemorrhage in women with hypertensive disorders of pregnancy are required to avert severe maternal outcomes.

Keywords: severe maternal outcomes, hypertensive disorders of pregnancy, maternal nearmiss, maternal mortality, sub-Saharan Africa

\section{Introduction}

Hypertensive disorders of pregnancy (HDPs) remain one of the leading causes of maternal mortality and severe morbidity. ${ }^{1-5}$ According to the World Health Organization (WHO), 14\% of global maternal deaths (MDs) in 2014 could be attributed to HDPs. ${ }^{6}$ In sub-Saharan Africa (SSA), HDPs are the second-leading cause of MDs and complications. ${ }^{6,7}$ In general, the incidence of preeclampsia/eclampsia is higher in Africa than any other region. ${ }^{8} \mathrm{~A}$ recent systematic review in Ethiopia showed a combined prevalence of preeclampsia/eclampsia of $5.5 \%$, with a wide gap
Correspondence: Abera Kenay Tura School of Nursing and Midwifery, College of Health and Medical Sciences, Haramaya University, POB 235, Harar, Ethiopa Email a.k.tura@haramaya.edu.et
International Journal of Women's Health 2020:12 255-263 
from $1.2 \%$ in a national study to $18.3 \%$ in a study conducted in public health institutions in southern Ethiopia. ${ }^{9}$ In the 2018 Ethiopian Maternal Death Surveillance and Response System report, $16 \%$ of MDs were due to HDPs. ${ }^{10}$

In the maternal health continuum, pregnancy may be uncomplicated or complicated by mild morbidity, potentially life-threatening conditions, life-threatening complications, or death. ${ }^{11}$ By applying this continuum to HDPs, preeclampsia may be classified as mild morbidity or severe preeclampsia and eclampsia as severe morbidity or potentially a lifethreatening condition, and maternal near-misses (MNMs) from preeclampsia/eclampsia as life-threatening complications preceding MD. Each course can be viewed from this perspective as a progressive chain of events leading to increasingly severe morbidity and ultimately to MD. Understanding the burden at each segment of the continuum and identifying factors affecting the progression from mild morbidity to lifethreatening complications (including mortality) is essential for designing appropriate interventions. ${ }^{12}$ To facilitate such studies, the WHO proposed MNM criteria, which had been previously found to be less applicable in low-income settings. ${ }^{13,14}$ Using a Delphi consensus approach, a panel of experts thus proposed an adaptation of these criteria: the SSA MNM criteria for use in low-income settings. ${ }^{15}$

Factors associated with severe maternal outcomes in HDPs have not been studied in Ethiopia. The objective of this study was to assess the occurrence of MNMs and MDs according to the WHO MNM criteria and its recent adaptation for SSA countries among women admitted with severe preeclampsia and eclampsia in a university and a regional hospital in eastern Ethiopia.

\section{Methods}

This study was a sub-analysis of a prospective study conducted on severe maternal morbidity in Hiwot Fana Specialized University Hospital and Jugel Hospital in Harar, eastern Ethiopia. ${ }^{16}$ Hiwot Fana is a tertiary-hospital affiliated with the College of Health and Medical Sciences of Haramaya University, where approximately 3,500 births take place annually. Jugel Hospital is a regional public hospital found in the same city, where approximately 2,000 births take place annually. Between January 2016 and April 2017, all cases of potentially life-threatening conditions (severe postpartum hemorrhage, severe preeclampsia, eclampsia, ruptured uterus, sepsis/severe systemic infection, severe complications of abortion) were prospectively identified on a daily basis and followed until discharge. ${ }^{16}$ During this period,1,054 women with potentially life-threatening conditions were admitted to both hospitals, of whom 562 were related to HDPs. A total of 7,929 deliveries resulting in 7,404 live births were registered in both hospitals during the same period (Figure 1).

We applied the definition of MNM according to the adapted $\mathrm{SSA}^{15}$ and WHO MNM criteria ${ }^{17}$ to women with severe preeclampsia and eclampsia. For each woman, we retrospectively evaluated the presence of MNM indicators according to the SSA and WHO criteria. SSA MNM criteria were developed for use in low-resource settings, where some of the WHO criteria that focus on organ dysfunction are difficult to apply. SSA MNM criteria include $27 \mathrm{MNM}$ indicators (including 19 from the 25indicator WHO MNM tool). The most important modification was lowering the threshold for number of units of blood for transfusion in major obstetric hemorrhage from five (in the original WHO MNM criteria) to two units and adding eclampsia, a clinical criterion, to the adapted tool. ${ }^{15}$ The comparison of the SSA and WHO MNM criteria with their respective definitions is shown in Table $\mathrm{S} 1$.

For all eligible women, data were collected prospectively on sociodemographic characteristics, obstetric conditions and complications, and maternal and perinatal outcomes at discharge. For the current study, we used information related to women having severe preeclampsia and eclampsia only. Case definitions for HDPs were: preeclampsia (new onset of hypertension with proteinuria after 20 weeks of gestation); severe preeclampsia (severe hypertension $>160$ / $110 \mathrm{mmHg}$ ) plus one of severe headache, blurring of vision, epigastric pain, creatinine $>1.1$, HELLP (hemolysis, elevated liver enzymes $[>2 \times]$, low platelet count $[<100,000]$ ) syndrome, or pulmonary edema; and preeclampsia with seizure(s) without history of epilepsy, including coma in preeclampsia. ${ }^{18}$ Data were collected from medical records after discharge. Trained nurse midwives collected the data under the supervision of the first author (AKT) and other senior researchers from the College of Health and Medical Sciences, Haramaya University.

\section{Data Processing and Analysis}

Data were entered using EpiData v3.1 (www.epidata.dk), and SPSS 23 (IBM, Armonk, NY, USA) was used for analysis. Descriptive statistics using frequencies and percentages were used to describe characteristics of participants. Presence of severe maternal outcomes (MNMs and MDs) according to SSA or WHO MNM criteria was the dependent variable. MNM indicators, such as MNM ratio, mortality index, and severe maternal outcome ratio, were 


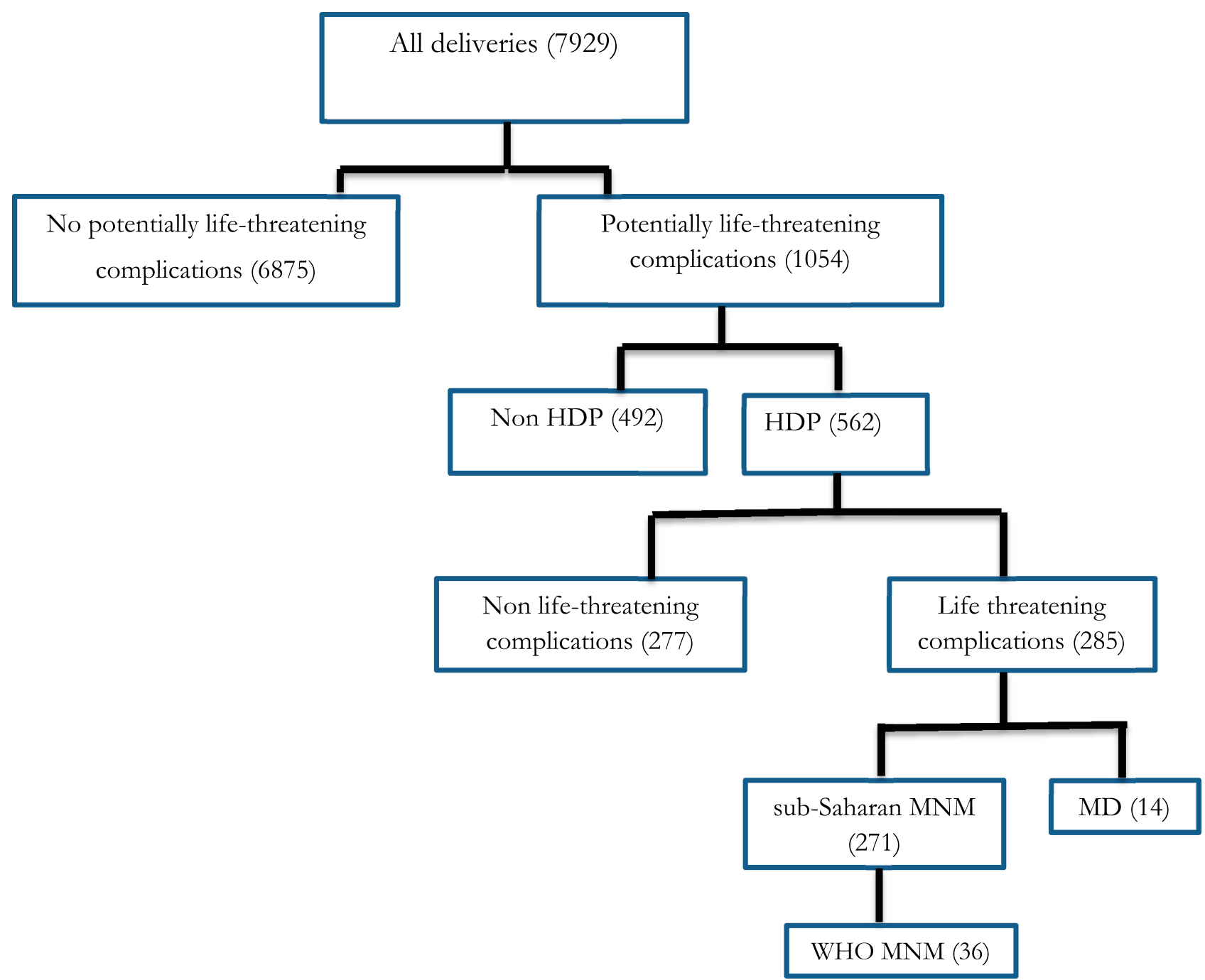

Figure I Flowchart of severe HDPs in eastern Ethiopia: comparing the original WHO and adapted sub-Saharan African MNM criteria.

Abbreviations: HDPs, hypertensive disorders of pregnancy; WHO, World Health Organization; MNM, maternal near miss; MDs, maternal death.

calculated and compared between the two classifications. The MNM ratio is the number of MNMs per 1,000 live births. The severe maternal outcome ratio is the of MNM ratio and MDs per 1,000 live births. The mortality index is the proportion of MDs from all women with severe maternal outcomes (MDs/[MNM + MDs]). Possible risk factors for developing severe maternal outcomes were first assessed using binary logistic regression. A multivariate model was then built, retaining variables for logistic regression if $p \leq 0.25$ in the binary model in either the SSA or WHO group. Level of statistical significance for the model was set at $p<0.05$.

\section{Ethical Considerations}

This study was conducted in accordance with the Declaration of Helsinki. The study protocol was reviewed and approved by the Institutional Health Research Ethics Review Committee of the College of Health and Medical Sciences, Haramaya University (C/A/R/D/01/1681/16) in Ethiopia. Data were collected after discharge of the women, and thus did not affect the course or outcome of treatment. Informed consent was not sought, since data were collected from medical records. No identifying information was collected.

\section{Results}

Of 562 women with potentially life-threatening conditions related to severe preeclampsia and eclampsia, the WHO MNM criteria identified 50 severe maternal outcomes (8.9\%): $36 \mathrm{MNMs}$ and $14 \mathrm{MDs}$, while SSA MNM criteria identified 285 (50.7\%): 271 MNMs and 14 MDs. The mean age of women in the WHO group, SSA group, and MDs were 25.0, 23.8, and 24.4 years, respectively. 
No antenatal care, preterm births, and multiparity were commoner among the WHO group and MDs compared to the SSA group. No other significant differences were observed among the three groups (Table 1).

Severe preeclampsia and eclampsia complicated 337 $(4.3 \%)$ and $225(2.8 \%)$ of all births during the study period $(n=7,929)$. All women with eclampsia and 60with severe preeclampsia (17.8\%) fulfilled the SSA MNM criteria, while only 25 with eclampsia $(11.6 \%)$ and 24 with severe preeclampsia (7.1\%) fulfilled the WHO MNM criteria.

Table I Sociodemographic Characteristics of Study Participants

\begin{tabular}{|c|c|c|c|c|}
\hline & $\begin{array}{l}\text { SSA, } \\
n=285 \text { (\%) }\end{array}$ & $\begin{array}{l}\text { WHO, } \\
n=50 \text { (\%) }\end{array}$ & $\begin{array}{l}\text { MDs, } \\
n=14 \text { (\%) }\end{array}$ & $p$-value \\
\hline $\begin{array}{l}\text { Age in years, } \\
\text { mean }( \pm \mathrm{SD})\end{array}$ & $23.8( \pm 5.5)$ & $25.0( \pm 5.6)$ & $24.4( \pm 4.8)$ & \\
\hline$<20$ & $53(18.6)$ & $6(12.0)$ & $2(14.3)$ & 0.770 \\
\hline $20-34$ & 207 (72.6) & $38(76.0)$ & II (78.6) & \\
\hline$\geq 35$ & $25(8.8)$ & $6(12.0)$ & I (7.1) & \\
\hline \multicolumn{5}{|l|}{ Referred } \\
\hline Yes & 184 (64.8) & $35(70.0)$ & $13(92.9)$ & 0.081 \\
\hline No & 100 & $15(30.0)$ & I (7.I) & \\
\hline \multicolumn{5}{|l|}{ Booked for ANC } \\
\hline Yes & $94(33.0)$ & $9(18.0)$ & $2(14.3)$ & 0.043 \\
\hline No & $191(67.0)$ & $4 \mid(82.0)$ & $12(85.7)$ & \\
\hline \multicolumn{5}{|l|}{$\begin{array}{l}\text { Gestational age } \\
\text { (weeks) }\end{array}$} \\
\hline$<28$ & $10(5.5)$ & $2(5.7)$ & I (12.5) & 0.049 \\
\hline $28-36$ & $103(56.6)$ & $28(80.0)$ & $6(75.0)$ & \\
\hline$\geq 37$ & 69 (37.9) & $5(14.3)$ & I (I2.5) & \\
\hline \multicolumn{5}{|l|}{ Gravida } \\
\hline 1 & I38 (48.6) & $17(34.0)$ & $6(42.8)$ & 0.030 \\
\hline $2-4$ & 91 (32.0) & $13(26.0)$ & $4(28.6)$ & \\
\hline$>4$ & $55(19.4)$ & $20(40.0)$ & $4(28.6)$ & \\
\hline \multicolumn{5}{|l|}{$\begin{array}{l}\text { Number of } \\
\text { children }\end{array}$} \\
\hline 0 & III (38.9) & $14(28.0)$ & $3(21.4)$ & 0.060 \\
\hline $1-4$ & $128(44.9)$ & $20(40.0)$ & $7(50.0)$ & \\
\hline$\geq 5$ & $46(16.2)$ & $16(32.0)$ & $4(28.6)$ & \\
\hline \multicolumn{5}{|l|}{ Mode of delivery } \\
\hline Vaginal & $193(67.7)$ & $33(70.2)$ & $9(64.3)$ & 0.903 \\
\hline $\begin{array}{l}\text { Cesarean } \\
\text { section }\end{array}$ & $92(32.3)$ & $14(29.8)$ & $5(35.7)$ & \\
\hline \multicolumn{5}{|l|}{ Admission date } \\
\hline Working day & $200(70.2)$ & $38(76.0)$ & $9(64.3)$ & 0.608 \\
\hline $\begin{array}{c}\text { Not a } \\
\text { working day }\end{array}$ & $85(29.8)$ & $12(24.0)$ & $5(35.7)$ & \\
\hline
\end{tabular}

Notes: Bold values: respective Chi Square $\left(X^{2}\right)$ values for the significant ones are as follows: for ANC: $X^{2}$ cal =6.2705; Gestational age: $X^{2}$ cal=9.5597; Gravida: $X^{2}$ cal=10.7168. Abbreviations: ANC, antenatal care; SSA, sub-Saharan Africa; WHO, World Health Organization, MDs, maternal deaths.
The severe preeclampsia/eclampsia-related MNM ratio was 4.9 per 1,000 live births according to WHO MNM criteria and 36.6 according to SSA criteria. Details of severe preeclampsia/eclampsia-related complications and MNM indicators stratified by WHO or SSA MNM criteria are summarized in Table 2. Hemorrhage was diagnosed in eleven $(22 \%)$ women in the WHO group and $27(9.5 \%)$ in the SSA group. Blood products were administered to 38 $(13.3 \%)$ women, of whom only eleven $(3.9 \%)$ received five or more units (Table 3 ).

Concerning the distribution of MNM events in the two groups, respiratory dysfunction $(n=23)$ followed by coagulation dysfunction $(n=16)$ were commonest in the WHO group. In the SSA group, eclampsia $(n=225)$ followed by coagulation dysfunction $(n=34)$ were the most prevalent. Of 225 women with eclampsia, only $26(11.6 \%)$ fulfilled the WHO MNM criteria. The remaining ( $\mathrm{n}=199 ; 88.4 \%$ ) did not fulfill WHO MNM criteria, because organ dysfunction was not mentioned in their files. The mortality index was $28 \%$ for the WHO group and $4.9 \%$ in the SSA group. For all MNM events, unsurprisingly mortality indices were equal or higher in the WHO group compared to the SSA group (Table 4).

More than $80 \%$ of women in both groups had MNMs already on arrival or within 12 hours after admission. A majority of those with MNMs on arrival were referred from other facilities: $28(68.3 \%)$ in the WHO group and 163 $(64.9 \%)$ in SSA group. The mortality index was higher among women presenting to hospitals with MNMs compared to MNMs occurring in hospital after admission (Table 5). In women fulfilling SSA MNM criteria, severe maternal outcomes were higher in those who were referred (adjusted OR 1.97, 95\% CI 1.13-3.41), had not received antenatal care (adjusted OR 3.13, 95\% CI 1.775.54), and rural residents (adjusted OR 2.32, 95\% CI 1.11-4.87). In the WHO group, women with concomitant obstetric hemorrhage (adjusted OR 3.75, 95\% CI 1.10-12.76), who were referred (adjusted OR 3.34, 95\% CI 1.20-9.31), and with no antenatal care (adjusted OR 3.17, 95\% CI 1.03-9.76) were at increased risk of developing severe maternal outcomes. No statistically significant association was observed between severe maternal outcomes and age, gestational age, number of pregnancies, or mode of delivery in either group (Table 6).

\section{Discussion}

The MNM ratio among women with severe HDPs in eastern Ethiopia was 4.9 per 1,000 live births according to WHO MNM criteria and 36.6 according to the adapted 
Table 2 Distribution of HDP-related Complications and MNM Indicators in Eastern Ethiopia

\begin{tabular}{|c|c|c|c|c|c|c|c|c|c|c|c|c|c|c|c|}
\hline & \multirow[t]{2}{*}{ All HDPs, n (\%) } & \multicolumn{2}{|c|}{ All SMOs } & \multicolumn{2}{|c|}{ MNMs } & \multicolumn{2}{|c|}{ MNM Ratio } & \multirow[t]{2}{*}{ MMR } & \multicolumn{2}{|c|}{ SMO Ratio } & \multicolumn{2}{|c|}{ MNM:MDs } & \multicolumn{2}{|l|}{ MI } & \multirow[t]{2}{*}{ CFR } \\
\hline & & SSA & WHO & SSA & WHO & SSA & WHO & & SSA & WHO & SSA & WHO & SSA & WHO & \\
\hline SPE & $337(60)$ & 60 & 24 & 55 & 19 & 7.4 & 2.6 & 67.5 & 8.1 & 3.2 & 11 & 3.8 & 8.3 & 20.8 & 1.5 \\
\hline Eclampsia & $225(40)$ & 225 & 26 & 216 & 17 & 29.2 & 2.3 & 121.6 & 30.4 & 3.5 & 24 & 1.9 & 4.0 & 34.6 & 4.0 \\
\hline Total & $562(100)$ & 285 & 50 & 271 & 36 & 36.6 & 4.9 & 189.1 & 38.5 & 6.8 & 19.4 & 3.6 & 4.9 & 28.0 & 2.5 \\
\hline
\end{tabular}

Abbreviations: S-PE, severe preeclampsia; SSA, sub-Saharan Africa; WHO, World Health Organization; HDPs, hypertensive disorders of pregnancy; MNMs, maternal near-miss es; MMR, maternal mortality ratio; SMOs, severe maternal outcomes (MNMs + MDs); MDs, maternal deaths; MI, mortality index (MDs/SMOs × 100); CFR, casefatality rate.

Table 3 Distribution of Underlying and Contributing Factors of Severe Maternal Outcomes Among Women with HDPs in Eastern Ethiopia

\begin{tabular}{|c|c|c|}
\hline & $\begin{array}{l}\text { SSA Tool, } \\
\text { n (\%) }\end{array}$ & $\begin{array}{l}\text { WHO Tool, } \\
\text { n (\%) }\end{array}$ \\
\hline $\begin{array}{l}\text { Underlying complications } \\
\text { Total } \\
\text { Severe preeclampsia } \\
\text { Eclampsia }\end{array}$ & $\begin{array}{l}285 \\
60(2 I .1) \\
225(78.9)\end{array}$ & $\begin{array}{l}50 \\
24(48.0) \\
26(52.0)\end{array}$ \\
\hline $\begin{array}{l}\text { Obstetric hemorrhage* } \\
\text { Abortion-related } \\
\text { Abruptio placenta } \\
\text { Placenta previa } \\
\text { Uterine rupture } \\
\text { Postpartum hemorrhage } \\
\text { Other }\end{array}$ & $\begin{array}{l}27(9.5) \\
2(0.7) \\
5(1.8) \\
2(0.7) \\
3(1.1) \\
10(3.5) \\
5(1.8)\end{array}$ & $\begin{array}{l}\text { II (22.0) } \\
0 \\
2(4.0) \\
0 \\
2(4.0) \\
6(12.0) \\
1(2.0)\end{array}$ \\
\hline $\begin{array}{l}\text { Sepsis or severe systemic } \\
\text { infection* }\end{array}$ & $19(6.7)$ & $8(16.0)$ \\
\hline $\begin{array}{l}\text { Contributing factors } \\
\text { Anemia }(<7 g / d l) \\
\text { Previous cesarean section }\end{array}$ & $\begin{array}{l}31(10.9) \\
9(3.2)\end{array}$ & $\begin{array}{l}8(16.0) \\
2(4.0)\end{array}$ \\
\hline $\begin{array}{l}\text { Critical interventions or ICU } \\
\text { admission } \\
\text { Use of blood products } \\
\text { Admission to ICU } \\
\text { Cesarean section } \\
\text { Laparotomy }\end{array}$ & $\begin{array}{l}|4|(49.5) \\
38(13.3) \\
40(\mid 4.0) \\
87(30.5) \\
4(1.4)\end{array}$ & $\begin{array}{l}37(74) \\
\text { II }(22.0) \\
23(46.0) \\
13(26.0) \\
4(8.0)\end{array}$ \\
\hline
\end{tabular}

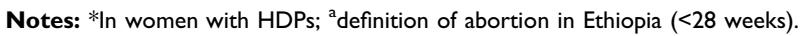
Abbreviation: ICU, intensive care unit.

SSA MNM criteria. Using the adapted SSA MNM criteria, we were able to identify robustly that severe maternal outcomes were higher among women who did not have any antenatal care, were referred from other facilities, and were rural residents. Increased risk of severe maternal outcomes among women with concomitant obstetric hemorrhage were observed among cases fulfilling WHO MNM criteria only, indicating the severity of these cases.
The contribution of severe HDPs among women with potentially life-threatening conditions $(53.3 \%)$ was comparable with other studies in Ethiopia ${ }^{19,20}$ and Nigeria. ${ }^{21}$ Severe maternal outcomes related to severe preeclampsia/ eclampsia according to WHO criteria (6.8 per 1,000 live births) was lower than a finding from Uganda (8.6) and much lower than that of Nigeria (24.0). ${ }^{5,22}$ It was higher, however, than in a study from Brazil (4.2). ${ }^{23}$ This may be related to differences in study setting and health-care systems. Our study was institution-based in a low institutional delivery $(26 \%)$ setting where most women with minor complications may not come to the hospital, where mainly high-risk women come. ${ }^{24}$

The risk of maternal mortality is higher among women with organ dysfunction (fulfilling the WHO MNM criteria) and highest among those with uterine dysfunction (60\%), followed by cardiovascular $(50 \%)$ and coagulation dysfunction (50\%). Although low in absolute number $(n=4)$, mortality was highest (75\%) among women who underwent laparotomy in the SSA group. Overall, the mortality index was $4.9 \%$ and $28 \%$ among cases in the SSA and WHO groups, respectively. The mortality index for WHO MNMs wass lower than in the study from Nigeria $(49.2 \%),{ }^{23}$ but higher than in the study from Uganda (8.3). ${ }^{5}$

Many women with severe maternal outcomes already have organ dysfunction on arrival, which makes treatment in hospitals too late to save the life of the woman or prevent organ failure. This advanced stage of illness on admission may be attributed to the low institutional delivery rate and a poorly functioning referral system. ${ }^{24,25}$ Community-level interventions are required for meaningful reductions in maternal mortality due to HDPs. ${ }^{25,26}$ Health workers in the community and lower district hospitals - who were capable of identifying and initiating treatment, but lack refresher training - should be refreshed on signs and symptoms, timely referral, and prophylactic use of magnesium sulfate. ${ }^{27-29}$ They should also be vigilant about the risk of obstetric hemorrhage, since this 
Table 4 Distribution of MNM Events in Women with HDPs in Eastern Ethiopia

\begin{tabular}{|l|l|l|l|l|l|l|}
\hline \multirow{2}{*}{} & \multicolumn{2}{l}{ Sub-Saharan Africa } & \multicolumn{2}{l|}{ World Health Organization } \\
\cline { 2 - 7 } & MNMs, n (\%) & MDs, n (\%) & MI (\%) & MNMs, n (\%) & MDs n (\%) & MI (\%) \\
\hline Cardiovascular dysfunction & $7(2.6)$ & $7(50.0)$ & 50.0 & $7(19.4)$ & $7(50.0)$ & 50.0 \\
Respiratory dysfunction & $15(5.5)$ & $8(57.1)$ & 34.8 & $15(41.7)$ & $8(57.1)$ & 34.8 \\
Uterine dysfunction & $2(0.7)$ & $3(21.4)$ & 60.0 & $2(5.6)$ & $3(21.4)$ & 60.0 \\
Coagulation dysfunction & $26(9.6)$ & $8(57.1)$ & 23.5 & $8(22.2)$ & $8(57.1)$ & 50.0 \\
Renal dysfunction & $1(0.4)$ & $1(7.1)$ & 50.0 & $1(2.8)$ & $1(7.1)$ & 50.0 \\
Hepatic dysfunction & $5(1.8)$ & $1(7.1)$ & 16.7 & $5(13.9)$ & $1(7.1)$ & 16.7 \\
Neurologic dysfunction & $7(2.6)$ & $6(42.9)$ & 46.2 & $7(19.4)$ & $6(42.9)$ & 46.2 \\
Eclampsia & $216(79.4)$ & $9(64.3)$ & 4.0 & $17(47.2)$ & $9(64.3)$ & 34.6 \\
Severe preeclampsia with ICU admission & $14(5.2)$ & $4(28.6)$ & 22.2 & $5(13.9)$ & $4(28.6)$ & 44.4 \\
Sepsis or severe systemic infections & $16(5.9)$ & $3(21.4)$ & 15.8 & $5(13.9)$ & $3(21.4)$ \\
Pulmonary edema & $6(2.2)$ & $2(14.3)$ & 25.0 & $4(11.1)$ & $2(14.3)$ \\
Total & $27 \mid(100)$ & $14(100)$ & 4.9 & $36(100)$ & $14(100)$ \\
\hline
\end{tabular}

Abbreviations: ICU, intensive care unit; MNMs, maternal near-misses; MDs, maternal deaths; MI, mortality index (MDs/MNM + MDs).

Table 5 SMOs and MNM Indicators Among Women with HDPs in Eastern Ethiopia

\begin{tabular}{|l|l|l|}
\hline \multirow{2}{*}{} & \multicolumn{2}{|l|}{ MNM Indicators } \\
\cline { 2 - 3 } & SSA & WHO \\
\hline $\begin{array}{l}\text { I. All live births in the population under } \\
\text { surveillance }\end{array}$ & 7404 & 7404 \\
\hline 2. SMOs (n) & & \\
MDs (n) & 285 & 50 \\
MNMs (n) & 14 & 14 \\
\hline 3. Overall near-miss indicators & 271 & 36 \\
SMO ratio (per I,000 live births) & & \\
MNM ratio (per I,000 live births) & 38.5 & 6.8 \\
MNM-mortality ratio (MNMs:MDs) & 36.6 & 4.9 \\
Mortality index (\%) & 19.4 & 2.6 \\
\hline 4. Hospital-access indicators & 4.9 & 28 \\
SMO cases presenting the organ dysfunction or maternal & 25 I & 41 \\
death within I2 hours of hospital stay (SMO ${ }_{12}$ n) & & \\
Proportion of SMO 12 cases among all SMO cases & 88.1 & 82.0 \\
Proportion of SMO 12 cases coming from other health & 64.9 & 68.3 \\
facilities & & \\
SMO I2 rate (per I,000 live births) & 33.9 & 5.5 \\
SMO 12 mortality index (\%) & 4.8 & 29.3 \\
\hline 5. Intrahospital care & & \\
Intrahospital SMOs (n) & 34 & 9 \\
Intrahospital SMO rate (per I,000 live births) & 4.6 & 1.2 \\
Intrahospital mortality index (\%) & 5.9 & 22.2 \\
\hline
\end{tabular}

Abbreviations: SMO, severe maternal outcome; SSA, sub-Saharan Africa; WHO, World Health Organization; MNM, maternal near-miss; MDs, maternal deaths.

appears to be a predilecting factor for severe maternal outcome among women with HDPs. ${ }^{30}$

Despite the reported high use of magnesium sulfate for prophylaxis $(95.8 \%)$ or treatment $(96.4 \%)$, lack of adequate intensive care units and late arrival of women results in a high mortality index. This highlights the need to assess quality of care or timeliness of prophylaxis or treatment. Further audits of appropriateness of management and opportunities for improvement (including prereferral management) are required to improve quality of obstetric care and avert preventable maternal mortality. ${ }^{31,32}$

Strengths of this study were the use of a prospective design in case selection and use of diagnosis made by the treating clinician. This study also had some limitations. First, although treatment with magnesium sulfate was assessed, data on its timing were not collected, and we are unable to comment about any delays. Second, we feel that incompleteness of medical records may affect our understanding about timing of prophylactic use of magnesium sulfate among women with eclampsia. We also feel that the existing low institutional delivery rate $(26 \%)$ may result in underestimation of the denominator (live births), ${ }^{24}$ since the majority of hospital births are among high-risk referred cases. ${ }^{33}$ Therefore, findings from this study may not reflect a population-based estimate of the condition.

In this low-resource setting, we feel that for audit purposes, the adapted SSA MNM tool should be used instead of the strict WHO tool, as the mortality index is still $4.9 \%$, indicating the severity of cases. ${ }^{15,34,35}$ Many lessons to be learned will be missed by lookingonly at the cases identified by the WHO MNM tool. One of the major aims of treatment is to prevent organ dysfunction in women with complications and thus focus on organ dysfunction, as identification criteria will not address this major task. Improvement of case detection in the 
Table 6 Factors Associated with Severe Maternal Outcomes Among Women with HDPs in Eastern Ethiopia

\begin{tabular}{|c|c|c|c|c|c|}
\hline & & \multicolumn{2}{|l|}{ SSA MNM Tool } & \multicolumn{2}{|c|}{ WHO MNM Tool } \\
\hline & & COR & aOR & cOR & aOR \\
\hline Age (years) & $\begin{array}{l}<20 \\
20-34 \\
\geq 35\end{array}$ & $\begin{array}{l}1.0 \\
0.67(0.42-1.06) \\
0.57(0.29-1.12)\end{array}$ & $\begin{array}{l}1.0 \\
1.70(0.76-3.78) \\
1.89(0.51-7.0)\end{array}$ & $\begin{array}{l}\text { I.0 } \\
\text { I.38 (0.57-3.38) } \\
\text { I.69 (0.52-5.54) }\end{array}$ & $\begin{array}{l}1.0 \\
3.55(0.57-22.29) \\
1.75(0.15-20.36)\end{array}$ \\
\hline Gravidity & $\begin{array}{l}1 \\
2-4 \\
\geq 5\end{array}$ & $\begin{array}{l}\text { I.0 } \\
0.67(0.45-0.98) \\
0.50(0.32-0.77)\end{array}$ & $\begin{array}{l}\text { I.0 } \\
\text { I.05 (0.48-2.27) } \\
0.77(0.37-1.62)\end{array}$ & $\begin{array}{l}1.0 \\
0.96(0.45-2.02) \\
2.27(1.14-4.50)\end{array}$ & $\begin{array}{l}1.0 \\
0.74(0.20-2.70) \\
1.65(0.47-5.78)\end{array}$ \\
\hline Referred & $\begin{array}{l}\text { No } \\
\text { Yes }\end{array}$ & $\begin{array}{l}1.0 \\
1.95(1.39-2.74)\end{array}$ & $\begin{array}{l}1.0 \\
1.97(1.13-3.41)\end{array}$ & $\begin{array}{l}1.0 \\
1.87(1.0-3.5 \mathrm{I})\end{array}$ & $\begin{array}{l}1.0 \\
3.34(1.20-9.31)\end{array}$ \\
\hline Received ANC & $\begin{array}{l}\text { Yes } \\
\text { No }\end{array}$ & $\begin{array}{l}1.0 \\
3.43(2.43-4.86)\end{array}$ & $\begin{array}{l}1.0 \\
3.13(1.77-5.54)\end{array}$ & $\begin{array}{l}1.0 \\
4.70(2.22-9.79)\end{array}$ & $\begin{array}{l}1.0 \\
3.17(1.03-9.76)\end{array}$ \\
\hline Mode of delivery ${ }^{a}$ & $\begin{array}{l}\text { Vaginal } \\
\text { CS }\end{array}$ & $\begin{array}{l}1.0 \\
0.71(0.49-1.01)\end{array}$ & $\begin{array}{l}1.0 \\
1.31(0.75-2.28)\end{array}$ & $\begin{array}{l}1.0 \\
0.68(0.35-1.33)\end{array}$ & $\begin{array}{l}1.0 \\
0.89(0.31-2.53)\end{array}$ \\
\hline Gestational age (weeks) & $\begin{array}{l}20-31 \\
32-36 \\
\geq 37\end{array}$ & $\begin{array}{l}1.0 \\
1.15(0.68-1.94) \\
1.00(0.59-1.69)\end{array}$ & $\begin{array}{l}1.0 \\
1.05(0.48-2.27) \\
0.77(0.37-1.62)\end{array}$ & $\begin{array}{l}\text { I.0 } \\
\text { I.26(0.55-2.89) } \\
0.28(0.09-0.85)\end{array}$ & $\begin{array}{l}1.0 \\
2.02(0.57-7.16) \\
0.31(0.07-1.40)\end{array}$ \\
\hline Hemorrhage & $\begin{array}{l}\text { No } \\
\text { Yes }\end{array}$ & $\begin{array}{l}1.0 \\
1.05(0.60-1.87)\end{array}$ & $\begin{array}{l}1.0 \\
2.37(0.98-5.76)\end{array}$ & $\begin{array}{l}1.0 \\
3.24(1.54-6.80)\end{array}$ & $\begin{array}{l}1.0 \\
3.76(1.10-12.76)\end{array}$ \\
\hline Address & $\begin{array}{l}\text { Urban } \\
\text { Rural }\end{array}$ & $\begin{array}{l}1.0 \\
3.76(2.13-6.63)\end{array}$ & $\begin{array}{l}1.0 \\
2.32(1.11-4.87)\end{array}$ & $\begin{array}{l}1.0 \\
2.68(0.80-9.04)\end{array}$ & $\begin{array}{l}1.0 \\
0.94(0.22-4.10)\end{array}$ \\
\hline
\end{tabular}

Note: "No delivery" and abortions excluded.

Abbreviations: SSA, sub-Saharan Africa; MNM, maternal near-miss; cOR, crude OR; aOR, adjusted OR; WHO, World Health Organization.

SSA tool was achieved by two notable changes: lowering the threshold of blood transfusion to at least two units and including eclampsia in MNM criteria. ${ }^{15}$ Lack of adequate blood for transfusion and limited resources for investigation could be the major reasons for (inevitable) underreporting of MNMs using the WHO criteria. In addition, in most hospitals in low-income settings, it is unlikely for a woman to receive five or more units of blood, due to restricted availability. ${ }^{36}$ Limited infrastructure for diagnosis or management and lack of specialists in intensive care make the use of the WHO criteria impractical in many low-resource settings.

In conclusion, the adapted SSA MNM tool identifies a larger number of cases amenable to audit than the WHO MNM tool, which may help in preventing organ dysfunction. The SSA MNM tool should be used for averting severe maternal outcomes related to HDPs, as reverting cases fulfilling the WHO MNM criteria is difficult because of organ dysfunction or failure. ${ }^{15,17}$ The majority of women with severe maternal outcomes reached hospitals in a critical condition, and thus an important key to improve outcomes of HDPs seems to be at lower-level facilities and in strengthening the referral system.
Quality of care for women with severe HDPs should be audited to identify areas of improvement and prevent organ dysfunction and MDs.

\section{Disclosure}

The authors report no conflicts of interest in this work.

\section{References}

1. Ngwenya S. Severe preeclampsia and eclampsia: incidence, complications, and perinatal outcomes at a low-resource setting, Mpilo Central Hospital, Bulawayo, Zimbabwe. Int J Womens Health. 2017;9:353-357. doi:10.2147/IJWH

2. Moodley J. Maternal deaths associated with hypertensive disorders of pregnancy: a population-based study. Hypertens Pregnancy. 2004;23 (3):247-256. doi:10.1081/PRG-200030301

3. Zhang J, Meikle S, Trumble A. Severe maternal morbidity associated with hypertensive disorders in pregnancy in the United States. Hypertens Pregnancy. 2003;22(2):203-212. doi:10.1081/PRG-1200 21066

4. Magee LA, Pels A, Helewa M, et al. The hypertensive disorders of pregnancy (29.3). Best Pract Res Clin Obstet Gynaecol. 2015;29 (5):643-657. doi:10.1016/j.bpobgyn.2015.04.001

5. Nakimuli A, Nakubulwa S, Kakaire O, et al. The burden of maternal morbidity and mortality attributable to hypertensive disorders in pregnancy: a prospective cohort study from Uganda. BMC Pregnancy Childbirth. 2016;16:205. doi:10.1186/s12884-016-1001-1 
6. Say L, Chou D, Gemmill A, et al. Global causes of maternal death: a WHO systematic analysis. Lancet Glob Health. 2014;2(6):e323e333. doi:10.1016/S2214-109X(14)70227-X

7. Khan KS, Wojdyla D, Say L, Gulmezoglu AM, Van Look PF. WHO analysis of causes of maternal death: a systematic review. Lancet. 2006;367(9516):1066-1074. doi:10.1016/S0140-6736(06)68397-9

8. Abalos E, Cuesta C, Grosso AL, Chou D, Say L. Global and regional estimates of pre-eclampsia and eclampsia: a systematic review. Eur J Obstet Gynecol Reprod Biol. 2013;170(1):1-7. doi:10.1016/j. ejogrb.2013.05.005

9. Berhe AK, Kassa GM, Fekadu GA, Muche AA. Prevalence of hypertensive disorders of pregnancy in Ethiopia: a systemic review and meta-analysis. BMC Pregnancy Childbirth. 2018;18(1):34. doi:10.1186/s12884-018-1667-7

10. Ethiopian Public Health Institute. Center for Public Health Emergency Management (PHEM). National Maternal Death Surveillance and Response (MDSR) Annual Report, 2009 EFY. 2018.

11. Ronsmans C, Filippi V. Reviewing severe maternal morbidity: learning from survivors of life-threatening complications. In: WHO, editors. Beyond the Numbers: Reviewing maternal Deaths and Complications to Make Pregnancy Safer Complications. Geneva: World Health Organization; 2004.

12. Ukah UV, De Silva DA, Payne B, et al. Prediction of adverse maternal outcomes from pre-eclampsia and other hypertensive disorders of pregnancy: a systematic review. Pregnancy Hypertens. 2017:S2210-7789(17)30332-X[pii]

13. van den Akker T, Beltman J, Leyten J, et al. The WHO maternal near miss approach: consequences at Malawian District level. PLoS One. 2013;8(1):e54805. doi:10.1371/journal.pone.0054805

14. Nelissen E, Mduma E, Broerse J, et al. Applicability of the WHO maternal near miss criteria in a low-resource setting. PLoS One. 2013;8(4):e61248. doi:10.1371/journal.pone.0061248

15. Tura AK, Stekelenburg J, Scherjon SA, et al. Adaptation of the WHO maternal near miss tool for use in sub-Saharan Africa: an International Delphi study. BMC Pregnancy Childbirth. 2017;17:445. doi:10.1186/s12884-017-1640-x

16. Tura AK, Zwart J, van Roosmalen J, Stekelenburg J, van den Akker T, Scherjon S. Severe maternal outcomes in eastern Ethiopia: application of the adapted maternal near miss tool. PLoS One. 2018;13(11):e0207350. doi:10.1371/journal.pone.0207350

17. Say L, Souza JP, Pattinson RC. WHO working group on Maternal Mortality and Morbidity classifications. Maternal near miss-towards a standard tool for monitoring quality of maternal health care. Best Pract Res Clin Obstet Gynaecol. 2009;23(3):287-296. doi:10.1016/j. bpobgyn.2009.01.007

18. Federal Ministry of Health, Ethiopia. Maternal Death Surveillance and Response (MDSR) Technical Guideline. 2014.

19. Liyew EF, Yalew AW, Afework MF, Essen B. Incidence and causes of maternal near-miss in selected hospitals of Addis Ababa, Ethiopia. PLoS One. 2017;12(6):e0179013. doi:10.1371/journal.pone.0179013

20. Gebrehiwot Y, Tewolde B. Improving maternity care in Ethiopia through facility based review of maternal deaths and near misses. Int J Gyn Obst. 2014;127(Supplement 1):S29-S34. doi:10.1016/j. ijgo.2014.08.003

21. Mbachu II, Ezeama C, Osuagwu K, Umeononihu OS, Obiannika C, Ezeama N. A cross sectional study of maternal near miss and mortality at a rural tertiary centre in southern Nigeria. BMC Pregnancy Childbirth. 2017;17:251. doi:10.1186/s12884-017-1436-z
22. Adamu A, Okusanya B, Tukur J, et al. Maternal near-miss and death among women with hypertensive disorders in pregnancy: a secondary analysis of the Nigeria Near-miss and Maternal Death Survey. BJOG. 2018.

23. Zanette E, Parpinelli MA, Surita FG, et al. Maternal near miss and death among women with severe hypertensive disorders: a Brazilian multicenter surveillance study. Rep Health. 2014;11:4. doi:10.1186/ 1742-4755-11-4

24. CSACE I. Ethiopia Demographic and Health Survey 2016. Addis Ababa, Ethiopia, and Rockville, Maryland, USA: CSA and ICF; 2016.

25. Austin A, Gulema H, Belizan M, et al. Barriers to providing quality emergency obstetric care in Addis Ababa, Ethiopia: healthcare providers perspectives on training, referrals and supervision, a mixed methods study. BMC Pregnancy Childbirth. 2015;15:74. doi:10.1186/ s12884-015-0493-4

26. von Dadelszen P, Magee LA. Preventing deaths due to the hypertensive disorders of pregnancy. Best Pract Res Clin Obstet Gynaecol. 2016;36:83-102. doi:10.1016/j.bpobgyn.2016.05.005

27. Sheikh S, Qureshi RN, Khowaja AR, et al. Health care provider knowledge and routine management of pre-eclampsia in Pakistan. Reprod Health. 2016;13(Suppl 2):104-116. doi:10.1186/s12978016-0215-z

28. Boene H, Vidler M, Augusto O, et al. Community health worker knowledge and management of pre-eclampsia in southern Mozambique. Reprod Health. 2016;13(Suppl 2):105-116. doi:10.1186/s12978-016-0220-2

29. Sotunsa JO, Vidler M, Akeju DO, et al. Community health workers' knowledge and practice in relation to pre-eclampsia in Ogun State, Nigeria: an essential bridge to maternal survival. Reprod Health. 2016;13(Suppl 2):108-116. doi:10.1186/s12978-016-0218-9

30. von Schmidt Auf Altenstadt JF, Hukkelhoven CW, van Roosmalen J, Bloemenkamp KW. Pre-eclampsia increases the risk of postpartum haemorrhage: a nationwide cohort study in the Netherlands. PLoS One. 2013;8(12):e81959. doi:10.1371/journal.pone.0081959

31. Kidanto HL, Wangwe P, Kilewo CD, Nystrom L, Lindmark G. Improved quality of management of eclampsia patients through criteria based audit at Muhimbili National Hospital, Dar es Salaam, Tanzania. Bridging the quality gap. BMC Pregnancy Childbirth. 2012;12:134. doi:10.1186/1471-2393-12-134

32. Kidanto HL, Mogren I, Massawe SN, Lindmark G, Nystrom L. Criteria-based audit on management of eclampsia patients at a tertiary hospital in Dar es Salaam, Tanzania. BMC Pregnancy Childbirth. 2009;9:13-2393. doi:10.1186/1471-2393-9-13

33. Kebede A, Hassen K, Nigussie Teklehaymanot A. Factors associated with institutional delivery service utilization in Ethiopia. Int J Womens Health. 2016;8:463-475. doi:10.2147/IJWH.S109498

34. Spector J. Practical criteria for maternal near miss needed for low-income settings. Lancet. 2013;382(9891):504-505. doi:10.1016/ S0140-6736(13)61710-9

35. Tuncalp O, Hindin MJ, Adu-Bonsaffoh K, Adanu RM. Assessment of maternal near-miss and quality of care in a hospital-based study in Accra, Ghana. Int J Gyn Obst. 2013;123(1):58-63. doi:10.1016/j. ijgo.2013.06.003

36. Bates I, Chapotera GK, McKew S, van den Broek N. Maternal mortality in sub-Saharan Africa: the contribution of ineffective blood transfusion services. BJOG. 2008;115(11):1331-1339. doi:10.1111/bjo.2008.115.issue-11 
International Journal of Women's Health

Dovepress

\section{Publish your work in this journal}

The International Journal of Women's Health is an international, peerreviewed open-access journal publishing original research, reports, editorials, reviews and commentaries on all aspects of women's healthcare including gynecology, obstetrics, and breast cancer. The manuscript management system is completely online and includes a very quick and fair peer-review system, which is all easy to use. Visit http://www.dovepress.com/testimonials.php to read real quotes from published authors.

Submit your manuscript here: https://www.dovepress.com/international-journal-of-womens-health-journal 